\title{
INCISION AND DRAINAGE OF PERIANAL ABSCESS WITH PRIMARY FISTULOTOMY IN CASE OF CO- EXISTING LOW VARIETY FISTULA
}

\author{
MASUM MNH ${ }^{1}$, YAZDANI A ${ }^{2}$, BISWAS MS ${ }^{3}$, MASUM ${ }^{4}$, BHUIYAN MA ${ }^{5}$, HOSSAIN NM ${ }^{6}$, \\ RAHMAN MA ${ }^{7}$
}

\begin{abstract}
Background: Perianal abscess is a clinical condition frequently encountered by surgeons. Perianal abscess originates from an infection arising in the cryptoglandular epithelium lining the anal canal. Occasionally; bacteria, fecal material or foreign matter can clog an anal gland and tunnel into the tissue around the anus or rectum, where it may then collect in a cavity called an abscess. About half of perianal abscess may manifest as fistula-in-ano which increases the risk of abscess recurrence requiring repeated drainage. Treating the fistula at the same time of incision and drainage of abscess reduce chances of recurrent abscess development and therefore likelihood of repeat surgery. Primary fistulotomy in case of low variety fistula may be advantageous for perianal abscess because fistulas are more commonly traceable and can be laid open with full preservation of external anal sphincters.
\end{abstract}

Methods: 216 consecutive patients (91.6\% males, 8.33\% females); mean age, 39 (range 18-70 years) from July, 2015 to January, 2019 with perianal abscesses were treated by incision and drainage and primary fistulotomy. 38 patients had comorbidities as diabetes mellitus, obesity (BMI>26), tuberculosis. Patients were followed up clinically for 2 months. Digital rectal examination performed to assess anal tone before, one week and one month after surgery.

Results: Operative time was on average 17 minutes (15-20 minutes). Average hospital stay was 1 day and complete healing time ranged from 30-60 days. Persistent fistulas developed in four patients after surgery (1.85\%). Bleeding occurred in 2 patients (1\%). Many patients had transient minor incontinence in the form of flatus and loose stool incontinence but eventually resolved after two weeks. No major incontinence was found. Patient's satisfaction of the treatment maneuver in relation to abscess recurrence and fistula occurrence was $95 \%$. All patients remained fully continent. Operative time, hospital stay, and time for complete wound healing were the same in both groups.

Conclusion: Primary fistulotomy for co-existing low variety fistula at the time of drainage of perianal abscess results in very few persistent fistulas and no added risk of fecal incontinence.

Key words: perianal abscess, primary fistulotomy, incision and drainage, fistula-in-ano.

J Dhaka Med Coll. 2019; 28(1) : 85-89

\section{Introduction:}

Fistula tract formation is a potential complication after incision and drainage of perianal abscess. Study report showed that in about $50 \%$ cases, chronic fistula-in-ano occurs after incision and drainage of anorectal abscess. ${ }^{1}$ Perianal abscess is one of the most common surgical emergencies encountered in clinical practice and its surgical management is one of the most common emergency surgical procedures performed by the surgeons ${ }^{[2]}$.

1. Dr. Mohammad Nazmul Hoque Masum, Associate professor, department of surgery, Dhaka Medical college Hospital

2. Dr. Asif Yazdani, Honorary Medical Officer, department of surgery, Dhaka Medical college Hospital

3. Dr. Md. Shahnawas Biswas, Resident, Department of surgery, Dhaka Medical College Hospital.

4. Dr. Mohammad Masum, Indoor medical officer, Department of surgery, Dhaka Medical College Hospital.

5. Dr. Masfique Ahmed Bhuiyan, Indoor Medical Officer, Department of surgery, Dhaka Medical College Hospital.

6. Dr. Md. Nabir Hossain, Associate Professor, Department of Surgical Oncology, National Institute of Cancer Research and Hospital , Dhaka

7. Dr. Md. Atiar Rahman, Associate Professor, Department of Surgery, Shaheed M Monsur Ali Medical College, Sirajgonj Correspondence to: Md. Nazmul Hoque Masum, Associate professor, department of surgery, Dhaka Medical College Hospital. 
Perianal abscesses arise from anal glands or cryptoglandular epithelium which have a predisposition to get obstructed and suppurated leading to abscess formation. Perianal abscesses and anal fistula are often found together ${ }^{3}$. A fistula develops as the result of spontaneous perforation of the abscess and tracking down through any of these five routes: ischiorectal, transsphincteric, intersphincteric, extrasphincteric and submucosal. While the initial treatment of perianal abscess is simple incision and drainage, other surgical procedures as fistulotomy may be required as a definitive measure for treating fistula because about $40 \%$ of patients present with a fistula after simple incision and drainage of their perianal abscesses ${ }^{2,4}$. Surgical intervention is recommended in case of spontaneous perforation since insufficient drainage may cause abscess recurrence or fistula formation. Conservative treatment options, particularly antibiotic treatment, are unlikely successful and are not considered appropriate [5]. Conventionally in many centers simple incision and drainage of perianal abscess without manipulation of fistulous tract is practised. But different randomized trials showed that primary fistulotomy at the time of abscess drainage is safe and efficient ${ }^{6}$. The aim of this study is to show the outcome of incision and drainage of perianal abscess with primary fistulotomy in case of low-variety fistula. Concomitant drainage with fistulotomy reduces the chance of recurrence of abscess and fistula formation.

\section{Patients and Methods:}

A total number of 216 patients of both sexes; 198 males and 18 females, their ages ranged between 18- 70 years were enrolled to this prospective study and they were subjected to drainage \& fistulotomy for acute perianal abscess. The study started from July, 2015 to January, 2019 and was conducted in private clinics in Dhaka, Brahmonbaria and Dhaka medical college hospital. The study included all patients having first attack of perianal abscess with underlying low lying fistula tract. Patients with recurrent abscesses or presence of fistula with previous history of perianal abscess, highvariety fistula-in-ano detected at the time of operation were excluded. Informed written consents were obtained from all patients before the study. 38 patients had co-morbidities in the form of diabetes mellitus $(\mathrm{N}=22), \mathrm{BMI}>26$ $(\mathrm{N}=15)$, Tuberculosis $(\mathrm{N}=1)$ patients (Table 1$)$. The steps of procedure were explained to all patients. All the operative maneuvers were performed under spinal anaesthesia with patients in the lithotomy position. Abscess drainage was done after cruciate incision and the internal opening was searched using the anal probe. Then fistulotomy was done. Hemostasis was achieved. Patients were discharged on the first postoperative day and were advised regarding oral medication, maintenance of local hygiene, hip bath after defecation, dressings, and regular follow-up. The primary end points of the study were incontinence, abscess recurrence, fistula formation. Abscess recurrence and fistula formation were diagnosed on the clinical background according the decision of two examiners. Incontinence was assessed by using the Fecal Incontinence Severity Index (FISI), that allow patients to record the frequency of accidental leakage with gas, mucus, liquid, and/ or solid stool:

1) No accidental leakage from anus (no fecal/ flatal incontinence [no FI/FL]),

2) Leakage of gas only (isolated flatal incontinence only [isolated FL]), or

3) Accidental leakage of mucus, liquid or solid stool with or without leakage of gas (fecal incontinence $[\mathrm{FI}]$ with or without flatal incontinence) ${ }^{7}$.

Table-I

Patient Demographics

\begin{tabular}{lc}
\hline Parameter & Number \\
\hline Age range (Mean) & 18-70 years (39 years) \\
Total patient: & 216 \\
Male & 198 \\
Female & 18 \\
Comorbidities: & 38 \\
Diabetes Mellitus & 22 \\
BMI $>26$ & 15 \\
Tuberculosis & 01 \\
\hline
\end{tabular}


The secondary end points were time off from work, wound discharge, wound healing and patient's satisfaction. Time off from work was defined as the number of days between the day of surgery and the first day a patient returned to work ${ }^{[8]}$. Postoperative wound discharge was defined as a non-infected sero-sanguinous secretion coming from the open wound while complete healing of the postoperative wound was defined as full epithelialization of the wound [9]. Patients' satisfaction was measured according to abscess recurrence, fistula formation and occurrence of incontinence.

\section{Results:}

In our series, $92 \%$ of our patients were gentlemen, 38\% were e"50 years old and 36.5 $\%$ were diabetic. There was neither operative nor postoperative mortality. The operating time for the procedure was calculated from the start of abscess drainage to the beginning of dressing of the postoperative wound. The mean operative time in patients 17 minutes. Fistula recurrence rate was $1.85 \%$. Patient's satisfaction of the treatment maneuver in relation to fistula recurrence was $96 \%$. Regarding the occurrence of fecal incontinence, no permanent cases were reported in our series but temporary flatus and loose stool incontinence was observed in 82 patients. According to Fecal Incontinence Severity Index, none of our patients showed fecal incontinence, 60 patients were temporarily incontinent to gases and 12 patients to loose stool, those subsided gradually after 2 weeks and all the women had this transient problem. We detected that $98 \%$ patient was satisfied with the treatment maneuver. The time taken for wound to heal completely according to the proposed protocol in our methodology was 3060 days with mean value 45 days. As regard the time taken for complete wound healing, we detected that 5 patients were unsatisfied of the treatment maneuver. The overall patient satisfaction was calculated in our study as the sum of individual satisfaction for each parameter according the questionnaire prepared by the treating surgical team and signed by the patients themselves. Regarding fistula recurrence, patient's satisfaction of the treatment maneuver was $96 \%$. In case of anal incontinence, there was $98 \%$ of patients seemed satisfied after 2 weeks. For the time taken for wound discharge to cease and that taken for wound to heal completely, patient satisfaction was shown in table 2 . Therefore, the overall patient satisfaction mean values was $96 \%$.

Table-II

Showing number of complications and patient satisfaction rate

\begin{tabular}{lcc}
\hline Parameters & $\begin{array}{c}\text { Complications } \\
(\mathrm{N})\end{array}$ & $\begin{array}{c}\text { Patient } \\
\text { Satisfaction (\%) }\end{array}$ \\
\hline Fistula & 4 & 96 \\
Bleeding & 2 & 98 \\
Incontinence after & 0 & 98 \\
2 weeks & & \\
Wound discharge & 10 & 77 \\
\hline Total: Mean \pm SD & & $96 \pm 1.8$ \\
\hline
\end{tabular}

\section{Discussion:}

In the present study, the male gender predominance $(92 \%)$, and those with age $\leq 50$ years $(48 \%)$ came in concordance with those reported in studies of same interest ${ }^{10,11}$ and other studies reported that perianal abscesses are seen two times more frequently in men than in women ${ }^{3,5,12}$. In agreement with our finding, it was stated that the peak incidence of perianal abscesses is in the third or fourth decade of life and it is two or three times more common in men than women with diabetes and increased BMI as the major traced risk factors for development of perianal abscesses ${ }^{13,14}$. Our study finding showed no abscess recurrence whereas other published data reported abscess recurrence rate $5 \%$ of the fistulotomy group [15, 16]. Benjelloun EB et al. showed in his study that recurrence rate was in $8 \%$ patients after drainage and fistulotomy ${ }^{6}$. Aly Saber et al. reported in a comparative study among 200 patients between drainage alone and drainage with fisulotomy that fistula recurred in $2 \%$ patient $^{25}$.

The decision of whether or not to perform a fistulotomy during the original incision and drainage of perianal abscess has been debated in the literature ${ }^{3,17}$. In a randomized clinical trial done by Oliver and colleagues compared 
simple drainage abscess drainage with and without fistula track treatment to evaluate the effectiveness and morbidity of both operations in the management of acute anal sepsis. They found that drainage of the abscess with fistulotomy can be safely performed in cases of subcutaneous, intersphincteric, or low transsphincteric fistula with a minimal recurrence rate as 5\% compared with 29\% recurrence rate in patients treated with drainage alone ${ }^{16}$. Incontinence rates following fistulotomy depends on both the amount of muscle divided at the time of operation as well as any preexisting previous sphincter damage causing scarring of the anal canal ${ }^{3,18,19 .}$ Incontinence rates have been reported in previous reports to range from $18 \%$ to $52 \% 3$, 20,21 . Oliver and his colleagues found zero $(0$ $\%)$ incontinence in drainage only and 6\% in drainage with fistulotomy [16]. Regarding the time to complete healing, the mean time was 18 (range 10-53) days and 26 (range 18-40) days after drainage alone versus fistulotomy respectively ${ }^{17,22 .}$ Aly Saber et al. reported that total healing time was about $31.8+8$ days in average after drainage and fistulotomy ${ }^{25}$. These results comply with our study findings as we had $1.85 \%$ fistula recurrence, wound healing was on average 45 days ranging from 30-60 days.

Patient satisfaction after surgery for anal diseases depends on factors like period of hospitalization, postoperative pain and bleeding, return to routine activity, wound care, wound healing time, interference with the anal continence and recurrence. In ither study, the majority of patients subjected to surgery for anal problems attributed their dissatisfaction to recurrence and anal incontinence following surgery ${ }^{23}$. In our study, patient satisfaction was satisfactory regarding treatment by abscess drainage and fistulotomy, less wound discharge and lower incidence of fistula formation. Other study reports have proved that optimal surgical management for ischiorectal abscess appears to be incison and drainage and fistulotomy, resulting in a lower recurrence rate and comparable morbidity as compared to incision and drainage alone ${ }^{24}$.

\section{Conclusion:}

Our study findings confirm that fistulotomy is an efficient and safe treatment of anal abscess with good long-term results, specially in case of low-variety fistula. Although high-variety fistula were excluded from our study, studies should be conducted regarding high fistula-inano also. The main aim of performing fistulotomy along with incion and drainage is to reduce patient hazards regarding multiple operative procedures, increase patient compliance, reduce cost and financial burden. So, fistulotomy during incion and drainage of abscess in case of low-variety fistula-in-ano should be the choice as there is no real chance of incontinence, and very significantly low chance of abscess and fistula recurrence.

\section{References:}

1. Whiteford MH. Perianal abscess/fistula disease. Clin Colon Rectal Surg. 2007 May. 20(2):102-9

2. Malik A, Hall D, Devaney R, Sylvester H, Yalamarthi $\mathrm{S}$. The impact of specialist experience in the surgical management of perianal abscesses. Int J Surg. 2011; 9(6): 475-7.

3. Sneider EB, Maykel JA. Anal abscess and fistula. Gastroenterol Clin North Am. 2013; 42(4): 773-84.

4. Hamadani A, Haigh PI, Liu IL, Abbas MA. Who is at risk for developing chronic anal fistula or recurrent anal sepsis after initial perianal abscess? Dis Colon Rectum, 2009 (52): 217-221.

5. Ommer A, Herold A, Berg E, Fürst A, Sailer M, Schiedeck T. German S3 guideline: anal abscess. Int J Colorectal Dis. 2012;27: 831-837.

6. Benjelloun, E.B., Jarrar, A., El Rhazi, K. et al. Updates Surg (2013) 65: 207. https://doi.org/10.1007/ s13304-013-0218

7. Imhoff LR, Brown JS, Creasman JM, Subak LL, Van den Eeden SK, Thom DH, Varma MG, Huang AJ. Fecal incontinence decreases sexual quality of life, but does not prevent sexual activity in women. Dis Colon Rectum. 2012; 55(10): 1059-65.

8. Saber A, Ellabban GM, Gad MA and Elsayem K. Open preperitoneal versus anterior approach for recurrent inguinal hernia: a randomized study. BMC Surgery 2012, 12:22 doi: 10.1186/1471-2482-12-22.

9. Jain BK, Vaibhaw K, Garg PK, Gupta S and Mohanty D. Comparison of a Fistulectomy and a Fistulotomy with Marsupialization in the Management of a Simple Anal Fistula: A Randomized, Controlled Pilot Trial. J Korean Soc Coloproctol. 2012; 28(2): 78-82. 
10. Czeiger D, Shaked G, Igov I, Pinsk I, Peiser J, Sebbag G. High occurrence of perianal abscess among Bedouin compared to Jews in the southern region of Israel. BMC Surg. 2013; 12; 13: 35. doi: 10.1186/ 1471-2482-13-35.

11. De Oliveira PG; de Sousa JB; de Almeida RM; Wurmbauer IFS; dos Santos CAN and Filho JG. Anal fistula: results of surgical treatment in a consecutive series of patients. J. Coloproctol. (Rio J.), 2012; 32 (1): 60-64.

12. Abcarian H. Anorectal infection: abscess-fistula. Clin Colon Rectal Surg. 2011, 24 (1): 14-21.

13. Ulug M, Gedik E, Girgin S, Celen MK, Ayaz C. The evaluation of bacteriology in perianal abscesses of 81 adult patients. Braz J Infect Dis. 2010; 14(3): 2259.

14. Wei PL, Keller JJ, Kuo LJ, Lin HC. Increased risk of diabetes following perianal abscess: a populationbased follow-up study. Int J Colorectal Dis. 2013; 28(2): 235-40.

15. Rizzo JA, Naig AL, Johnson EK. Anorectal abscess and fistula-in-ano: evidence-based management. Surg Clin North Am. 2010; 90(1): 45-68.

16. Oliver, F. J. Lacueva, F. P. Vicente, et al. Randomized clinical trial comparing simple drainage of anorectal abscess with and without fistula track treatment. Int J Colorectal Dis, 2003, 18; 107-110.

17. Malik AI, Nelson RL, Tou S. Incision and drainage of perianal abscess with or without treatment of anal fistula. Cochrane Database Syst Rev. 2010, 7; (7): CD006827. doi: 10.1002/14651858.CD006827.
18. Ege B, Leventoðlu S, Mentep BB, Yýlmaz U and Oner AY. Hybrid seton for the treatment of high anal fistulas: results of 128 consecutive patients. Tech Coloproctol. 2014; 18(2): 187-193.

19. Bokhari S, Lindsey I. Incontinence following sphincter division for treatment of anal fistula. Colorectal Dis. 2010; 12: 35-39.

20. Sharma D, Pipariya PR, Gupta S, Gupta A and Chopra N. Fistulectomy or Fistulotomy: Better Approach in Fistula-In- Ano. Sch. J. App. Med. Sci., 2014; 2(1B): 202-204.

21. Quah HM, Tang CL, Eu KW, et al. Meta-analysis of randomized clinical trials comparing drainage alone vs primary sphincter-cutting procedures for anorectal abscessfistula. Int $\mathrm{J}$ Colorectal Dis 2006; 21(6): 602-9.

22. Inceoglu R and Gencosmanoglu R. Fistulotomy and drainage of deep postanal space abscess in the treatment of posterior horseshoe fistula. BMC Surgery 2003, 3:10 doi: 10.1186/1471-2482-3-10.

23. Saber A. Patients Satisfaction and Outcome of Fistulotomy versus Fistulectomy for Low Anal Fistula. Journal of Surgery. Special Issue: Gastrointestinal Surgery: Recent Trends. 2016, 4(2-1): 15-19.

24. Cox SW, Senagore AJ, Luchtefeld MA, Mazier WP. Outcome after incision and drainage with fistulotomy for ischiorectal abscess. The American surgeon. 1997 Aug;63(8):686-689.

25. Aly Saber, Emad K. Bayumi. Perianal Abscess; Simple Drainage versus Drainage and Fistulotomy. Journal of Surgery. Special Issue: Surgical Infections and Sepsis. Vol. 4, No. 3-1, 2016, pp. 10-13. 